\title{
Verbesserte Dichtung durch DLC-Schichten
}

\author{
Eine neuartige trocken laufende Dichtung gewährleistet hohe Robustheit und \\ niedrige Kosten im Betriebseinsatz. Grundlegende Voraussetzung dafür ist eine speziell \\ angepasste DLC-Schicht, die besonders günstige Reibeigenschaften und eine hohe \\ Korrosions- und Verschleißfestigkeit zeigt.
}

D ie Verarbeitung chemisch aggressiver oder hochreiner Stoffe stellt hohe Anforderungen an Dichtungssysteme in Rührwerken oder Mischern der chemischen und petrochemischen Industrie, der Lebensmittelverarbeitung und Pharmazie. Die Dichtungen müssen trocken laufen, da Gas- oder Flüssigkeitsschmierungen die zu verarbeitenden Medien verunreinigen könnten. Um die Betriebskosten gering zu halten, ist es darüber hinaus wichtig, dass sie auch in ätzenden und hochkorrosiven Umgebungen über einen langen Zeitraum einwandfrei funktionieren. Forscher des Fraunhofer-Instituts für Schicht- und Oberflächentechnik IST und Interseal, einem Hersteller von Dichtungsanwendungen, haben eine neuartige trocken laufende Dichtung für hochkorrosive Umgebungen entwickelt, die sich durch eine hohe Robustheit und niedrige Betriebskosten auszeichnet.

Auf die trocken laufenden Edelstahldichtungen des Baukastensystems dry 9000 wird eine wenige Mikrometer dünne Schicht auf Basis von diamantähnlichem Kohlenstoff (DLC) abgeschieden. Durch einen speziell angepassten Schichtaufbau lässt sich die Dichtungsoberfläche so einstellen, dass sie sehr korrosions- und verschleißfest ist und darüber hinaus besonders günstige Reibeigenschaften zeigt. Die Schicht macht eine Sperrdruckanlage überflüssig und schließt eine Kontaminationsgefahr aus.

„Die hauchdünne DLC-Beschichtung kann auf Edelstähle aufgebracht

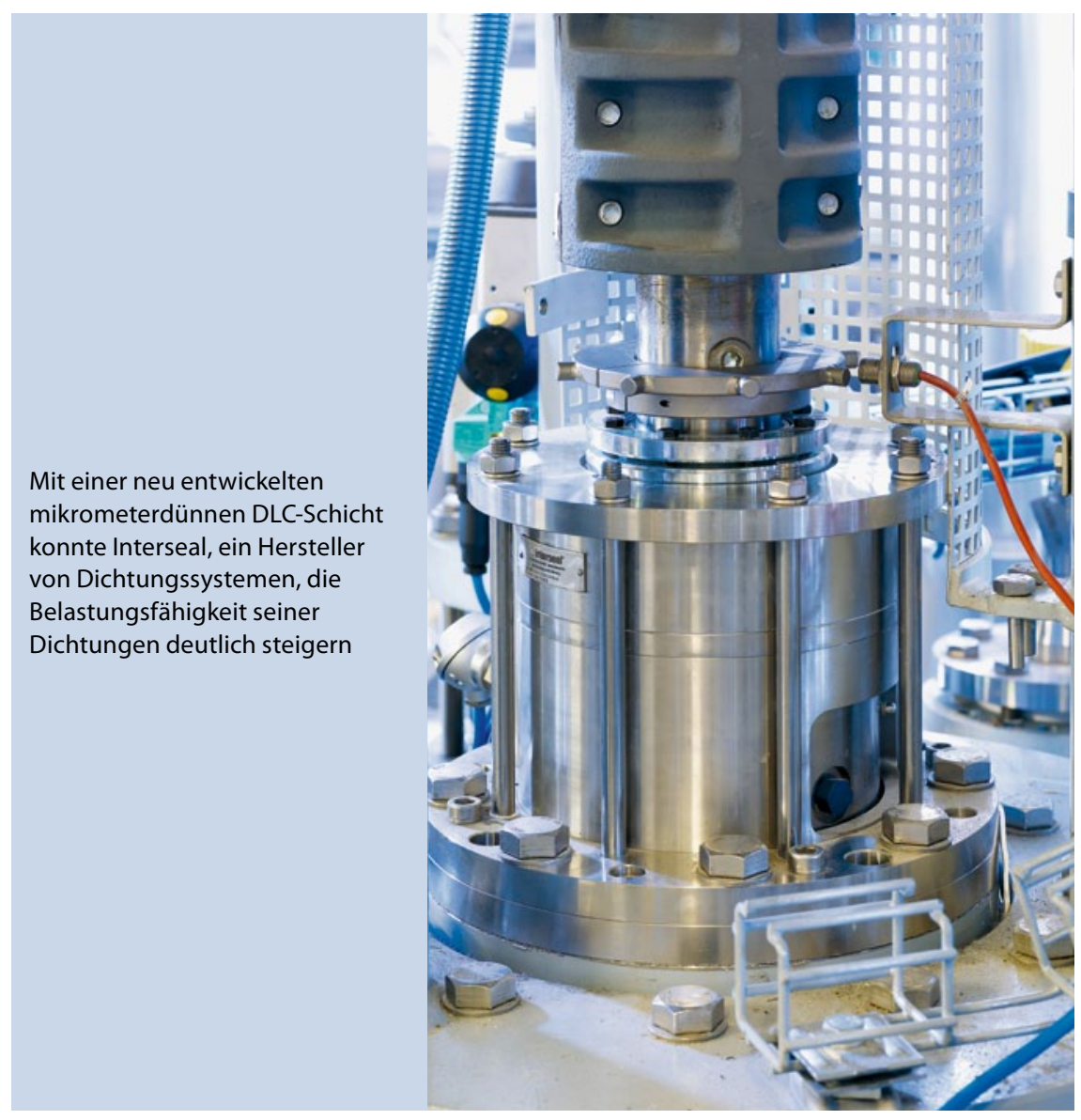

werden und hält stärksten Beanspruchungen stand. Dadurch verlängern sich die Standzeiten der Dichtungssysteme deutlich", so Dr. Jochen Brand, Abteilungsleiter Transferzentrum Tribologie am Fraunhofer IST, ,außerdem kann auf sehr teure Materialien wie Tantal und Nickelbasiswerkstoffe oder auch auf mechanisch empfindliche Werkstoffe wie $\mathrm{SiC}$ verzichtet werden." Mit dem neuen Dichtungssystem können beispielsweise Pharmaunternehmen zukünftig hochreine oder sterile Produkte wesentlich sicherer und ohne aufwendige Speziallösungen herstellen. I

\section{Kontakt:}

Fraunhofer-Institut für Schicht- und Oberflächentechnik IST, Braunschweig,

Tel.05312155 536, info@ist.fraunhofer.de

www.ist.fraunhofer.de 